\title{
Holocord Syrinx, Tethered Cord and Diastematomyelia: Case Report and Review of Literature
}

\author{
Maheshwari A', Yadav D², Aneja $S^{3}$, Kaur $S^{4}$, Patra B ${ }^{5}$, Seth $A^{6}$ \\ ${ }^{1}$ Dr. Anu Maheshwari, MBBS. MD. Assistant Professor. ${ }^{2}$ Dr. Dinesh Yadav, MBBS, MD, Senior Resident, ${ }^{3}$ Dr. Satinder \\ Aneja, MBBS, MD, Director Professor, ${ }^{4}$ Dr. Satnam Kaur, MBBS, MD, Senior Resident. ${ }^{5}$ Dr. Bijoy Patra, MBBS, MD, Senior \\ Pediatrician, ${ }^{6}$ Dr. Anju Seth, MBBS, MD, Professor. All from the department of Paediatrics, Lady Hardinge Medical College, \\ New Delhi, India.
}

Address for correspondence: Dr. Dinesh Yadav, E-mail: dineshmamc@gmail.com

\begin{abstract}
Syringomyelia refers to the presence of cavities within the spinal cord or a dilatation of the central spinal cord canal. In $90 \%$ of cases, syringomyelia is associated with a Chiari I malformation. The association of syringomyelia with tethered cord is well known but syrinxes associated with these defects are usually below vertebral level T6. Holocord syrinx associated with tethered cord is rare and is almost always associated with Chiari 1 malformation. To the best of our knowledge, only a single case report of holocord syrinx with tethered cord has been reported, but this patient had multiple overt lumbosacral defects (tethered cord, meningocele and diastematomyelia). We are reporting a three year old child with holocord syrinx with tethered cord and diastematomyelia and no evidence of Chiari malformation, meningocele or any overt spinal malformation and minimal neurological abnormalities.
\end{abstract}

\section{Introduction}

$S^{\prime}$ yringomyelia refers to presence of cavities within the spinal cord or a dilatation of the central spinal cord canal. In $90 \%$ of cases, syringomyelia is associated with a Chiari I malformation', where the cerebellar tonsils descend through the foramen magnum and disrupt the normal CSF flow ${ }^{2}$. Less commonly, syringomyelia may be associated with other obstructive lesions at the foramen magnum as well as spinal cord trauma, intramedullary tumors, infection, cord tethering, and developmental anomalies (i.e., diastematomyelia). The association of syringomyelia with tethered cord and spinal dysraphisms like diastematomyelia is well known and these defects are usually seen below vertebral level $\mathrm{T6}^{3}$. Holocord syrinx associated with tethered cord is rare and is almost always associated with Chiari 1 malformation ${ }^{4}$. To the best of our knowledge, only a single case report of holocord syrinx with tethered cord has been reported, but this patient had multiple overt lumbosacral defect (tethered cord, meningocele and diastematomyelia) ${ }^{5}$. We are reporting a 3 year old child with holocord syrinx with tethered cord and diastematomyelia and no evidence of Chiari malformation, meningocele or any overt spinal malformation and minimal neurological abnormalities.

\section{The Case}

A three year old male child was brought with gradual onset, progressively increasing clumsiness and frequent falls while walking since last three months. He was apparently well prior to this period and attained all developmental milestones at normal age. Child was appropriately toilet trained with normal bladder and bowel function. He had no difficulty in getting up from supine position or weakness of upper limbs. There was no history of trauma, fever, headache, vomiting or seizures during this period. He was first born child of non consanguineous marriage and perinatal period was uneventful.

On examination, child was hemodynamically stable without any signs of respiratory distress. General physical examination showed no pallor, icterus, lymphadenopathy or neuro-cutaneous markers. Neurological examination revealed abnormal gait with slight high stepping of the left foot. Higher mental functions, cranial nerves, sensory examination and muscle bulk were normal. Power testing of lower limbs revealed weakness (power 4/5) of tibialis anterior, tibialis posterior, peroneus longus, gastrocnemius, extensor 


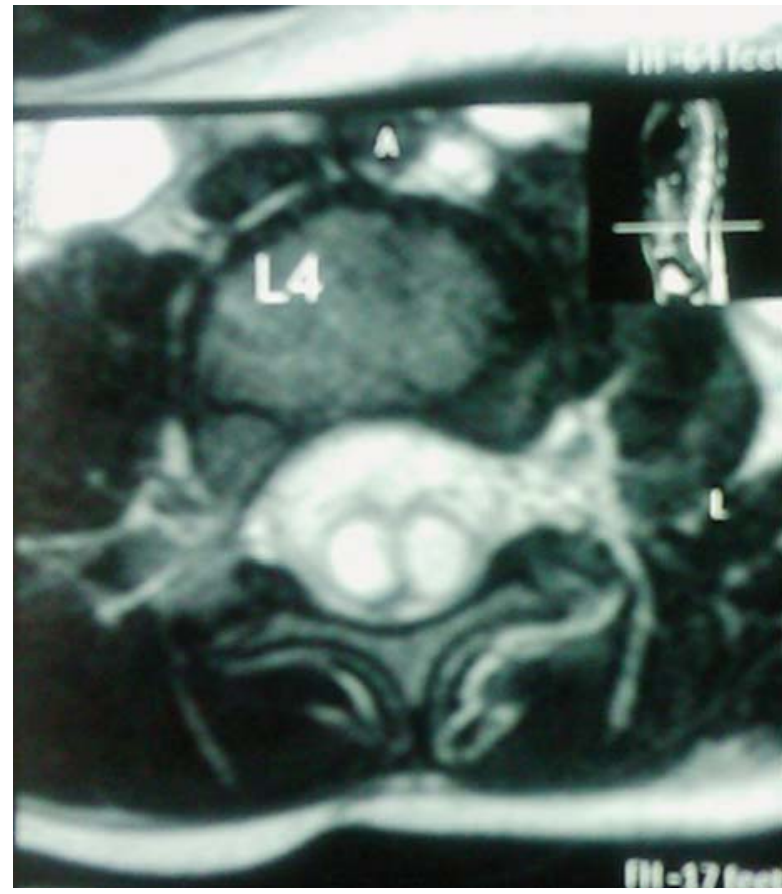

Fig 1: MRI Lumbar spine (L4) transverse section showing diastematomyelia and tethered cord.

hallucis longus and toe flexors with normal power in other muscle groups. Left patellar and ankle reflexes were brisk. Reflexes on right side and both upper limbs were normal. He had asymmetrically upgoing plantars, more prominent on left side. Spinal examination did not reveal any kyphoscoliosis, evidence of occult spinal dysraphism or localized tenderness.

Investigations revealed normal hemogram and serum biochemistry. X-ray lumbo-sacral spine did not reveal kyphoscoliosis or decrease in intervertebral space. Magnetic Resonanse Imaging (MRI) of spine demonstrated a holocord syrinx extending from cervical to lumbar spine with tethered cord and diastematomyelia at $L 5$ level. MRI of the brain was normal with no evidence of Arnold Chiari malformation. In view of progressively increasing symptoms, the child was referred to neurosurgeons for appropriate intervention.

\section{Discussion}

The association of syringomyelia with tethered cord syndrome has been well documented in literature ${ }^{6}$. In a retrospective analysis, Erkan et $\mathrm{al}^{3}$ found that $24 \%$ of patients with tethered cord also had terminal syringomyelia, defined as syrinx location in the lower one third of the spinal cord. In another series of 90 cases of occult spinal dysraphism evaluated by MRI, terminal syringomyelia was reported in $27 \%$ cases $^{5}$, usually in association with a tight filum terminale and anorectal anomalies (67\%), meningocele (54\%), and diastematomyelia (38\%). Similar to Erkan's findings, all syringes examined were below T6 with the exception

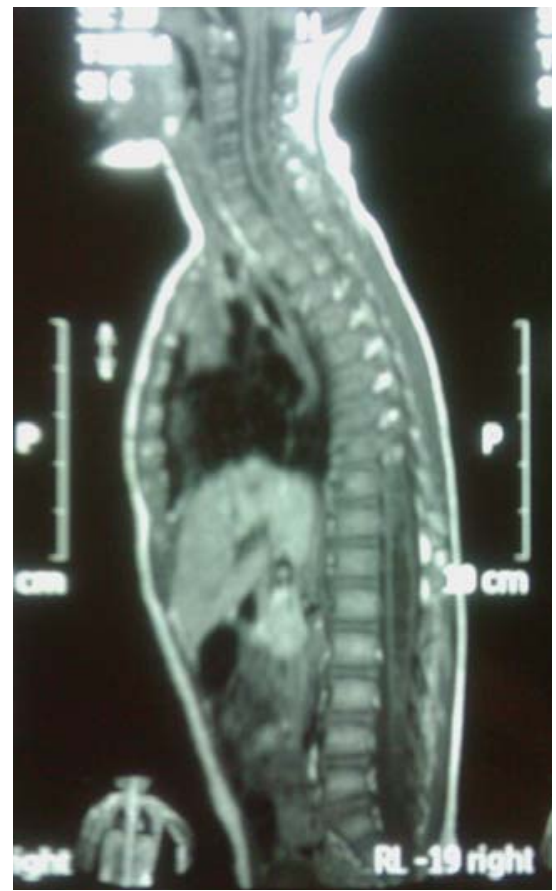

Fig 2: MRI Spine (Cervial to Lumbar spine) showing holocord syrinx most prominent in lower thoracic and lumbar spine.

of one patient with a holocord extension. This patient had multiple lumbosacral defects i.e, tethered cord, meningocele and diastematomyelia. Our patient had holocord syrinx with tethered cord and diastematomyelia with no evidence of meningocele or any cutaneous clue to underlying spinal pathology.

Despite numerous reports relating syringomyelia to tethered cord syndrome, the combined pathogenesis of the two disorders remains unclear. Some authors ${ }^{6}$ have proposed that terminal syrinx is an anomalous persistence of the ventriculus terminalis after defective retrogressive differentiation, while others ${ }^{3}$ have suggested that the pathogenesis of syringomyelia in cases of tethered cord is attributable to vascular and CSF flow alterations in the spinal cord. In addition, impaired CSF flow between cranial and spinal CSF may cause abnormal pulse pressure differentials, leading to cyst formation and expansion cephalad to the level of tethering.

Several studies suggest that syrinx drainage via syringosubarachnoid shunt placement in addition to surgical untethering can alleviate motor and sensory deficits ${ }^{3,5,7,8}$. Many studies recommend early prophylactic untethering before the onset or deterioration of neurologic deficits ${ }^{6}$.

\section{Conclusion}

In conclusion, the pathophysiology of syringomyelia remains complex and uncertain. The current literature favors tethered cord as the primary cause of syrinx 
formation. Prompt surgical intervention after detection of tethered cord may help prevent the progression of neurological deficits associated with syringomyelia and should therefore be considered. Ultimately, further research is needed for optimal management of syringomyelia associated with tethered cord to improve clinical outcomes.

\section{References}

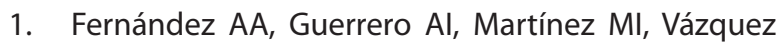
$M E$, Fernández JB, Chesaioctavio $E$, de Labrado JL, Silva ME, de Araoz MF, García-Ramos R, Ribes MG, Gómez C, Valdivia Jl, Valbuena RN, Ramón JR. Malformations of the craniocervical junction (Chiari type I and syringomyelia: classification, diagnosis and treatment). BMC Musculoskelet Disord 2009;10(Suppl I): S1-S11.

2. Ventureyra EC, Aziz HA, Vassilyadi M. The role of cine flow MRI in children with Chiari I malformation. Childs Nerv Syst 2003;19:109-113.
3. Erkan K, Unal F, Kiris T. Terminal syringomyelia in association with the tethered cord syndrome. Neurosurgery 1999;45:1351-9.

4. McMillan HJ, Sell E, Nzau M, Ventureyra ECG. Chiari 1 malformation and holocord syringomyelia presenting as abrupt onset foot drop. Childs Nerv Syst $2011 ; 27(1): 183-6$. Epub 2010 Sep 2.

5. Iskandar BJ, Oakes WJ, McLaughlin C, Osumi AK, Tien RD. Terminal syringohydromyelia and occult spinal dysraphism. J Neurosurg 1994;81:513-9.

6. Hsu AR, Hou LC, Veeravagu A, Barnes PD, Huhn SL. Resolution of syringomyelia after release of tethered cord. Surgical Neurol 2009;72:657-61.

7. Caldarelli M, Di Rocco C, La Marca F. Treatment of hydromyelia in spina bifida. Surg Neurol 1998;50:41120.

8. Koyanagi I, Iwasaki Y, Hida K, Abe H, Isu T, Akino M. Surgical treatment of syringomyelia associated with spinal dysraphism. Childs Nerv Syst 1997;13:194-200.

\section{How to cite this article?}

Maheshwari A, Yadav D, Aneja S, Kaur S, Patra B, Seth A. Holocord Syrinx, Tethered Cord and Diastematomyelia: Case Report and Review of Literature. J Nepal Paediatr Soc 2012;32(2):169-171. 